\title{
Calling amplitude flexibility and acoustic spacing in the territorial frog Allobates femoralis
}

\author{
Camilo Rodríguez $^{1,2}$ (D) $\cdot$ Adolfo Amézquita ${ }^{2} \cdot$ Max Ringler $^{1,3,4} \cdot$ Andrius Pašukonis $^{5} \cdot$ Walter Hödl $^{4}$
}

Received: 26 March 2020 / Revised: 23 May 2020 / Accepted: 25 May 2020 / Published online: 5 June 2020

(C) The Author(s) 2020

\begin{abstract}
Most male frogs produce calls to attract females and repel rivals. The transmission of these calls can be affected by many acoustic and environmental characteristics, which can influence the detection and decoding of the signal by the receiver. Calling-perch height has a strong influence on sound propagation and acoustic spacing with neighboring males, but how frogs optimize their calling behavior in this context is poorly understood. In this study, we investigated if and how frogs can adjust the calling energy in the context of acoustic spacing. Our aim was to evaluate the relationship between calling-perch height, nearest-neighbor distance, and sound-pressure level in the brilliant-thighed poison frog Allobates femoralis. We found that frogs flexibly adjust the calling amplitude according to the calling-perch height without affecting the effectiveness signal propagation. Accompanying signal propagation experiments demonstrated that calls produced with lower amplitude from higher perches propagate similar to louder calls from the ground. Our results suggest an adjustment to the hypothesis of a general positive effect of calling-perch height on signal effectiveness, where highly territorial frogs adjust their calling behavior to reduce energy expenditure and optimize acoustic communication with conspecifics.
\end{abstract}

\section{Significance statement}

In acoustically communicating species, sound propagates better when broadcasted from elevated positions. However, callers may adjust their calling behavior to optimize the sound transmission under ecological constraints. By using a correlative and manipulative approach, we show in a poison frog model that males can adjust their calling amplitude according to the calling-perch height. We then discuss that this calling adjustment optimizes the acoustic spacing between conspecific males and reduces energy consumption.

Keywords Calling amplitude $\cdot$ Calling-perch height $\cdot$ Nearest-neighbor distance $\cdot$ Dendrobatidae $\cdot$ Amplitude flexibility Acoustic spacing

Communicated by A. Taylor Baugh

Electronic supplementary material The online version of this article (https://doi.org/10.1007/s00265-020-02857-6) contains supplementary material, which is available to authorized users.

Camilo Rodríguez

camilo.rodriguez@univie.ac.at

1 Department of Behavioural and Cognitive Biology, University of Vienna, Vienna, Austria

2 Department of Biological Sciences, University of Los Andes, Bogotá, Colombia

3 Department of Ecology and Evolutionary Biology, University of California, Los Angeles, USA

4 Department of Evolutionary Biology, University of Vienna, Vienna, Austria

5 Department of Biology, Stanford University, Stanford, USA

\section{Introduction}

In acoustically communicating species, sound production and signal detection are critical for social interactions, such as species recognition and mating (Gerhardt 1994; Owings and Morton 1998). In anuran amphibians, acoustic communication determines the reproductive behavior where usually males produce calls to attract females (Gerhardt 1994). In territorial frogs, acoustic communication also mediates the acquisition and defense of territories by males (Gerhardt 1994; Pröhl 2005). For effective communication, the emitted signal containing certain information (e.g., species identity, position, reproductive motivation) must propagate, be received, and decoded by the receiver to influence its behavior (Wells and Schwartz 2007). 
The efficiency of information transfer is shaped by the sender's intrinsic morphological and energetic constraints on signal production (Hödl et al. 2004; Amézquita et al. 2006; Göd et al. 2007). Extrinsic environmental conditions (e.g., distance from the ground, vegetation structure, temperature; Wiley and Richards 1982; Gerhardt 1994; Narins et al. 2006; Bro-Jørgensen 2010) can additionally limit the propagation by sound attenuation and degradation. In frogs, sound attenuation (Brenowitz et al. 1984; Robertson 1984; Wilczynski and Brenowitz 1988; Brenowitz 1989; Gerhardt et al. 1989) and degradation (Ringler et al. 2017) have been shown to affect the phonotactic response of both males and females, and the calling responses of neighboring males, resulting in modified mate choice and male spacing patterns. Excess attenuation, i.e., the reduction of sound-pressure level (SPL) beyond loss through spherical spreading, can provide additional information on habitat characteristics and the distance of the sender, and thus further influence the response of a signal's receiver (Marten and Marler 1977; Wiley and Richards 1982).

In complex acoustic environments, where acoustically communicating species face acoustic attenuation and degradation, abiotic acoustic interference, and the competition for acoustic space, callers should adjust their calling behavior to maximize signal effectiveness (Hödl 1977; Duellman and Pyles 1983; Gerhardt and Huber 2002). Calling at higher perches allows the signal to propagate over larger distances and thereby increases the likelihood of reaching intended receivers (e.g., females, conspecific intruders). This positive relationship between calling-perch height and sound propagation has been shown in insects (Walker and Forrest 1989), birds (Sorjonen 1986), and amphibians (Greer and Wells 1980; Wells and Schwartz 1982; Brenowitz et al. 1984; Kime et al. 2000; Parris 2002; Kats et al. 2012; Schwartz et al. 2015). However, animals can also adjust the amplitude of the signal depending on the level of masking abiotic and/or inter- and intraspecific background noise (Lombard 1911; Brumm and Todt 2002, 2004). For instance, signals with higher amplitude may counteract masking effects and travel farther and so be more easily detected by receivers (Lombard 1911; Forrest 1994). This noise-dependent vocal plasticity has been described in few species of amphibians (Halfwerk et al. 2016; Shen and Xu 2016; Zhao et al. 2018). However, to our knowledge, amplitude adjustment independent of masking background noise has only been demonstrated in the WhiteLipped Frog, Leptodactylus albilabris (Lopez et al. 1988). This species presents plasticity of the advertisement call amplitude in response to increasing-amplitude stimuli, suggesting a "shouting match" between directly competing males (Love and Bee 2010).

Among amphibians, Neotropical poison frogs (Dendrobatidae) present some of the most complex social behaviors, including a high degree of territoriality, different types of parental care, and acoustic communication (Lötters et al. 2007; Wells 2007). Males of the brilliant-thighed poison frog, Allobates femoralis, are strongly territorial, a behavior associated with prominent advertisement calls (Hödl 1983). Males therefore may benefit from producing calls that propagate as far as possible to better repel conspecific males and reach more females. Whereas specific temporal and spectral properties, sound-radiation patterns, behavioral aspects, evolutionary patterns, and adaptive consequences related to the advertisement call have been extensively studied in this species (Narins et al. 2003; Hödl et al. 2004; Amézquita et al. 2005; Amézquita et al. 2006; Göd et al. 2007; Gasser et al. 2009; de Luna et al. 2010; Rodríguez and Hödl 2020), little information exists on how males adapt their calling behavior to interfering habitat-induced factors to optimize signal effectiveness.

In a pilot experiment, we found that the calling-perch height in A. femoralis males was not positively related to sound propagation. This observation is quite surprising giving the strong evidence of such a positive effect in other anuran species (Greer and Wells 1980; Wells and Schwartz 1982; Brenowitz et al. 1984; Parris 2002), suggesting that the call amplitude and/or the calling-perch height can be adjusted by A. femoralis males in the context of territoriality and acoustic spacing. In this study, we addressed this issue with two different approaches: first, by relating natural calling-perch heights with the produced SPL and the inter-individual distances of calling A. femoralis males in two geographically distant populations; and second, by conducting signal propagation experiments to test the effect of calling-perch height on the SPL at the location of the receiver. Our specific aims were to test (1) whether males that call at higher perches deliver calls with higher amplitude at the receivers and therefore have larger nearest-neighbor distances (NNDs) than males that call at lower perches; (2) whether the calling amplitude and/or the calling-perch height are being flexibly adjusted by A. femoralis males; and (3) whether the calling-perch height has an effect on sound propagation under natural conditions.

\section{Methods}

\section{Study species and study area}

We conducted our study on the brilliant-thighed poison frog, Allobates femoralis Boulenger (1883; Dendrobatidae: Aromobatinae; AmphibiaWeb 2020). This species is terrestrial and diurnally active. The reproductive behavior consists of prolonged courtships involving auditory, visual, and tactile signals (Montanarin et al. 2011; Stückler et al. 2019). Males usually call from slightly elevated vegetation structures on the forest ground, like fallen trees, logs, lianas, and leaves (Roithmair 1992). Parental care is usually performed by males, who transport tadpoles to small water bodies 
(Roithmair 1992; Ringler et al. 2013). We conducted our study in two geographically distant populations of A. femoralis and in different years. First, we used 15 frogs from a population in the Tanimboca Natural Reserve near the city of Leticia in the Colombian Amazon ( $4^{\circ} 07^{\prime} \mathrm{S}-69^{\circ}$ 57' W; www.tanimboca.org) in July and August 2011 (from now on, Let11) and April 2014 (from now on, Let14). Later, we replicated the experiments using 34 frogs from a population near the "Pararé field camp," located in the Les Nouragues Natural Reserve in French Guiana ( $4^{\circ} 02^{\prime} \mathrm{N}-52^{\circ}$ 41' W; Bongers et al. 2013; see Ringler et al. (2015) for a description of the population characteristics), during the early reproductive season between February and April in 2018 (from now on, FG18) and in 2019 (from now on, FG19). Both study sites present structural and floristic heterogeneity. Detailed information about the structure and floristic composition is given in Bongers et al. (2001) for the "Pararé field camp," and CORPOAMAZONIA (2006) for Tanimboca.

We performed the experiments at the two sites in the same way (except for NND measurements; see below) and between 0700-1000 and 1500-1800, which corresponds to the peak calling activity of this species (Kaefer et al. 2012). We captured frogs using transparent plastic bags and measured their snout-urostyle length (SUL). We used digital images of the individually unique ventral patterns of $A$. femoralis for individual identification.

\section{Calling intensity, perch height, and nearest-neighbor distance}

We measured the sound-pressure level (SPL) of the advertisement call of $A$. femoralis males with a SPL meter (Voltcraft 329, Conrad Electronic SE, Wenberg Köblitz, Germany), using the peak detector in the C-weighting curve and in fast mode. The SPL meter was mounted either on a small tabletop or on a full-size tripod, aligned parallel to the forest floor, at the same height relative to the frog and pointing towards the frog with no vegetation in between. The frogs generally start calling with suboptimal advertisement calls of less than steady-state SPL, defined as "warm-up calls" (Jameson 1954; Toledo et al. 2014); therefore, we measured the SPL from the 5 th four-note call in a call series and we took the average of three SPL measurements after a linear conversion to pascals $\left(\mathrm{Pa}=20 \mu \mathrm{Pa} \cdot 10^{\mathrm{dB} / 20}\right)$. Because SPL measurements were taken at different distances (in a range of 0.24-3.1 m) from the calling frog, we fitted an exponential regression using the distance as a predictor and the logarithm of SPL as the response variable and used the residuals as the new distance-independent SPL (residuals (SPL)) in the subsequent statistical analysis. Snout-to-urostyle length (SUL) was not related to the $\operatorname{SPL}\left(F_{1,13}=2.13 ; P=0.16 ; R^{2}=0.07 ; N=\right.$ $15)$. Since $A$. femoralis males have a nearly omnidirectional sound radiation pattern (Rodríguez and Hödl 2020), the cardinal position of the frogs in reference to the SPL meter was registered, being $0 / 360^{\circ}$ the position of the SPL meter in the cardinal plane, in order to know whether the frogs' orientation affect the SPL measured in relation to the calling-perch height.

Subsequently, we measured the calling-perch height of the males from the exact spot where they were calling to the surface of the compacted leaf litter on the ground. Subsequently, we measured the NND as follows: In "Tanimboca," we measured the inter-individual distances from the exact spot where the frogs were calling by using measuring tapes. At the "Pararé field camp," we first performed a series of capture-recapture surveys only when the males were calling and recorded every capture point on a digital map of the study area (distance error estimate $\sim 10$ cm; Ringler et al. 2014) using pocket PCs (MobileMapper 10, Spectra Precision, Sunnyvale, CA, USA) with the mobile GIS software ArcPad (ESRI, Redlands, CA, USA). We used the traversing function in ArcPad to map the 2-D position of the frogs using laser range finders (DLE 50, Bosch, Gerlingen Germany) and precision compasses (Tandem (magnetic inclination zone 2), Suunto, Vantaa, Finland) for distance and direction measurements, respectively. Finally, we calculated the capture-point centroid for each male and measured the Euclidean distance between centroids to obtain NNDs in R (R Core Team 2017), using the "centroid" function of the Rpackage geosphere (Hijmans et al. 2017).

\section{Effect of perch height on sound propagation}

This experiment was conducted between February and April 2018 at the "Pararé field camp." To test the effect of callingperch height on sound propagation, we used an artificial call of $A$. femoralis featuring the average call properties from a nearby population (with a call consisting of four notes), approximately $30 \mathrm{~km}$ downstream on the Arataye river (for details on temporal and spectral parameters, see Narins et al. 2003; Gasser et al. 2009). We calibrated the loudspeaker with an integrated music player (Creative MUVO 2c, Creative, Singapore) at SPLs of 73, 76, and $81 \mathrm{~dB}$ using an SPL meter (Voltcraft 329) at 1-m distance by adjusting the volume setting. Then, we repeatedly broadcast playback signal three times at each SPL with the loudspeaker placed on logs at heights of 0,10 , and $20 \mathrm{~cm}$. We replicated 20 times the playback experiments using broadcast locations and directions within the natural habitat of the local $A$. femoralis population and selected opportunistically to let unobstructed playback paths between the speaker and the SPL meter. Both, the SPLs and heights were chosen to match the natural range of variation of the "Pararé field camp" population of $A$. femoralis (Table 1). SPL measurements of broadcast signals were taken at a horizontal distance of $6 \mathrm{~m}$ from the loudspeaker, which corresponds to the average territory radius of the "Pararé field 
Table 1 Descriptive statistics of calling behavior traits at "Tanimboca natural reserve" and "Pararé field camp." SPL = sound-pressure level; NND = nearest-neighbor distance

\begin{tabular}{|c|c|c|c|c|c|c|}
\hline \multirow[t]{2}{*}{ Site } & \multicolumn{2}{|l|}{ SPL (dB) } & \multicolumn{2}{|c|}{ Calling-perch height $(\mathrm{cm})$} & \multicolumn{2}{|l|}{ NND (m) } \\
\hline & $\overline{\mathrm{X}} \pm \mathrm{SD}$ & Range $(n)$ & $\overline{\mathrm{X}} \pm \mathrm{SD}$ & Range $(n)$ & $\overline{\mathrm{X}} \pm \mathrm{SD}$ & Range (n) \\
\hline Tanimboca & $71.60 \pm 2.94$ & $65-77.6(15)$ & $26.88 \pm 18.41$ & $2.78-72.6(15)$ & $13 \pm 6.9$ & $1.4-27(15)$ \\
\hline Pararé & $74.38 \pm 4.17$ & $64.23-81.5(34)$ & $13.22 \pm 6.23$ & $3-31.6(34)$ & $8.79 \pm 3.87$ & $4-17.41(30)$ \\
\hline
\end{tabular}

camp" population of A. femoralis (Ringler et al. 2011; Tumulty et al. 2018), with the SPL meter on the ground pointing towards the speaker.

\section{Repeatability of call amplitude and calling-perch height}

This experiment was conducted between February and April 2019 in the A. femoralis population near the "Pararé field camp." For each calling A. femoralis male, we measured the SPL and the height from their calling perch to the ground on three different occasions with minimum intervals of 3 days. To measure repeatability, we estimated the proportion of the total variance that is assigned to between-individual variation in the SPL and calling-perch height across the three different occasions (Nakagawa and Schielzeth 2010).

\section{Blinded methods}

To minimize observer bias, blinded methods were used when propagation experiments data were recorded and/or analyzed. However, for vocal behavior and repeatability measurements, it was not possible to record data blind because our experimental design involved focal animals in the field.

\section{Statistical analyses}

To estimate the relationship between the calling-perch height, call amplitude, and NND, we fitted linear mixed effects models by maximum likelihood using the "lmer" function within the lme4 package (Bates et al. 2015) in R ( $\mathrm{R}$ core Team 2017). As $p$ values for mixed effects models are not as easy to interpret as for linear models (Johansson 2011), we compared the likelihood of several models by using the "lrtest" function within the package lmtest (Zeileis and Hothorn 2002) in R. Prior to all comparisons, we evaluated whether the fixed effects were interdependent on each other or not (i.e., if the interaction matters), by comparing models with and without the interaction effect. Subsequently, in all cases, we compared a full model (including all the fixed effects) against a reduced model (excluding the fixed effect of interest in each comparison) as follows: (1) To evaluate the effect of calling-perch height on the call amplitude, we fitted a full model using calling-perch height and data sets (i.e., Let11, Let14, FG18, and FG19) as fixed factors, the individual intercepts as random factor, and residuals (SPL) as the response variable. The reduced model was identical but excluded the calling-perch height; (2) to evaluate the effect of the call amplitude on the NND, we fitted a full model using residuals (SPL) and data sets as fixed factors, the individual intercepts as random factor, and NDD as the response variable, the reduced model was identical but excluded the residuals (SPL); and (3) to evaluate the effect of the calling-perch height on the NND, we fitted a full model using calling-perch height and data sets as fixed factors, the individual intercepts as random factor, and the NND as the response variable. The reduced model was identical but excluded the calling-perch height. In all cases, we log-transformed the calling-perch height and square root-transformed the NND to fit a normal distribution. In each comparison, we assumed that the fixed effect had a significant effect when the difference between the likelihood of the full and reduced models was significant. Additionally, we performed simple linear regressions for every comparison in Let11, Let14, and FG18 data sets, and linear mixed regression in FG19. Furthermore, we estimated the effect of the frogs' orientation on the relationship between calling amplitude and calling-perch height by fitting a linear mixed effects model. We used the residuals (SPL) as the dependent variable, the interaction between calling-perch height and the orientation of the frog as fixed factor, and the ID of the frog as random factor. Likelihood ratio test was also performed between a full model (including the interaction) versus a null model (without the interaction).

To estimate the effect of the calling-perch height on signal propagation, we performed a linear mixed effects model using the received SPLs as response variable, the broadcast heights and SPLs as fixed effects, and repetitions and trials as nested random factors. Then, we used planned least-squares means contrasts using the "lsmeans" function within the lsmeans package (Lenth 2016). Post hoc comparisons were adjusted using Tukey's method for multiple comparisons. Significant statistical differences between the mean values would be indicated by non-overlapping $99.9 \%$ confidence intervals.

To estimate repeatability (R), we used the "rpt" function of the package $r p t R$ (Nakagawa and Schielzeth 2010) in R. In our fitted model, SPL or calling-perch height were used as the 
Fig. 1 Relationship between sound pressure levels (SPLs) and perch height in A. femoralis. a Fitted regression line from a linear regression mixed model with "data set" as a co-variable (diamonds: Let11 $(N=8)$; triangles: Let14 $(N=7)$; circles: $F G 18(N=22)$; squares: $F G 19(N$ $=12)$ ). $\mathbf{b}$ Simple linear regression models for every "data set." Shaded regions indicate $95 \%$ confidence intervals a

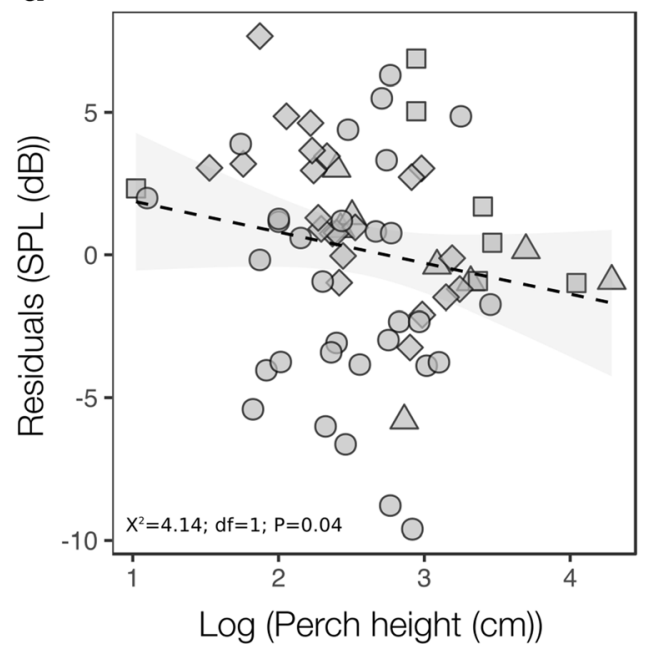

b

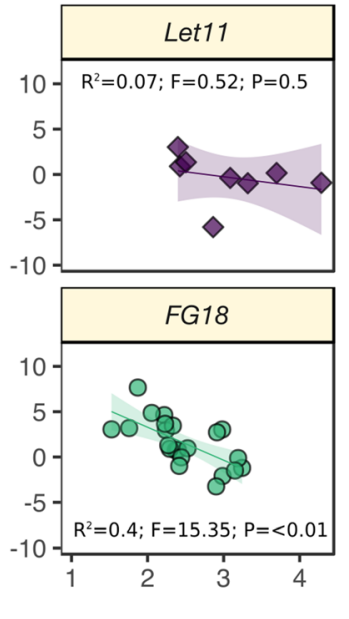

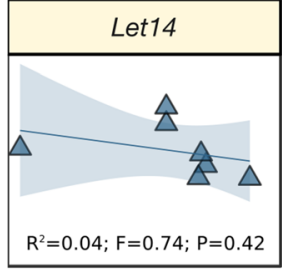

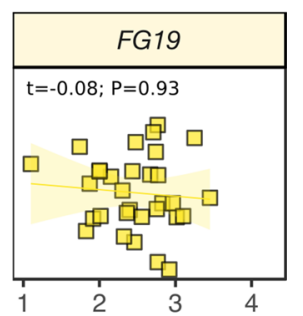

response variable, the data sets as the fixed factor, and the individual ID of the frog as the random factor. Statistical significance against the null hypothesis (repeatability $=0$ ) was estimated by likelihood ratio test.

\section{Results}

We found that $A$. femoralis males that perch higher produced calls at significant lower amplitudes $\left(X^{2}=4.14\right.$, df $=1, P=0.04$; Fig. 1a). While this effect was highly significant for the FG18 data set $\left(F=15.35, R^{2}=0.4, P<0.01\right.$; Fig. 1b), for the Let11, Let14, and FG19 data sets, it was not statistically significant (Let11: $F=0.52, R^{2}=0.07, P=0.5$; Let14: $F=0.74, R^{2}=0.04, P=0.42$; FG19: $t=-0.08, P=$ 0.93; Fig. 1b). Males producing higher amplitude calls did not have larger inter-individual distances to the nearest males $\left(X^{2}=0.02\right.$, df $=4, P=0.99$; Fig. 2a). Interestingly, in the FG18 data set, males had significant larger interindividual distances when calling at lower amplitudes $(t=$ $-2.3, R^{2}=0.2, P=0.03$; Fig. $\left.2 b\right)$, while this effect was not significant for the other data sets (Let11: $F=0.2, R^{2}=0.12$, $P=0.67$; Let 14: $F=0.56, R^{2}=0.07, P=0.48 ;$ FG19: $t=0, P$ $=1$; Fig. $2 \mathrm{~b}$ ). Moreover, higher perched males had larger inter-individual distances to the nearest males $\left(X^{2}=17.16\right.$, df $=4, P=0.001$; Fig. 3a). Nevertheless, while this effect was significant for the FG18 data $\operatorname{set}\left(F=4.42, R^{2}=0.16, P\right.$ $=0.05$; Fig. $3 \mathrm{~b}$ ) being not statistically significant for the Let11, Let14, and FG19 data sets (Let11: $F=4.5, R^{2}=$ $0.33, P=0.07$; Let14: $F=0.54, R^{2}=0.08, P=0.5$; FG19: $t=0, P=1$; Fig. $3 \mathrm{~b}$ ), the relationship between calling-perch height and calling amplitude was not interdependent on the frog's orientation when the SPL was measured $\left(X^{2}=4.9\right.$, $\mathrm{df}=3, P=0.17$ ).
Fig. 2 Relationship between nearest-neighbor distance (NND) and sound-pressure levels (SPL) in A. femoralis. a Fitted regression line from a linear regression mixed model with "data set" as a co-variable (diamonds: Let11 $(N=8)$; triangles: Let14 $(N=7)$; circles: FG18 $(N=18)$; squares: FG19 ( $N$ =12)). $\mathbf{b}$ Simple linear regression models for every "data set." Shaded regions indicate 95\% confidence intervals

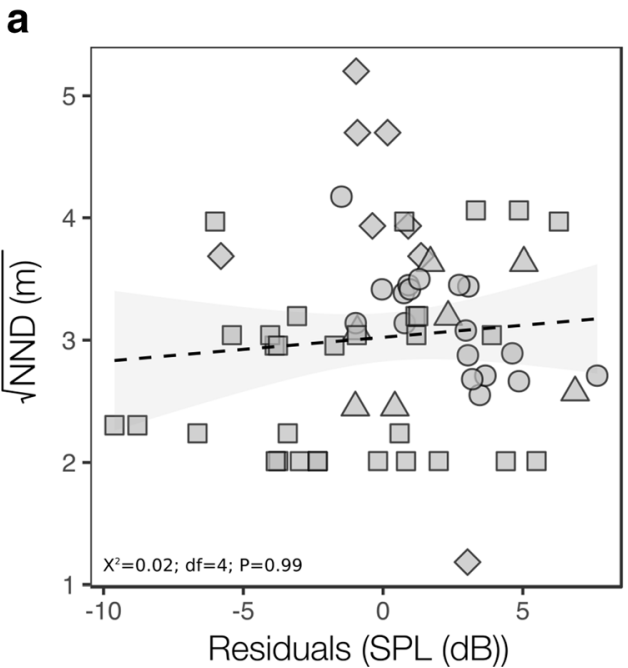

b

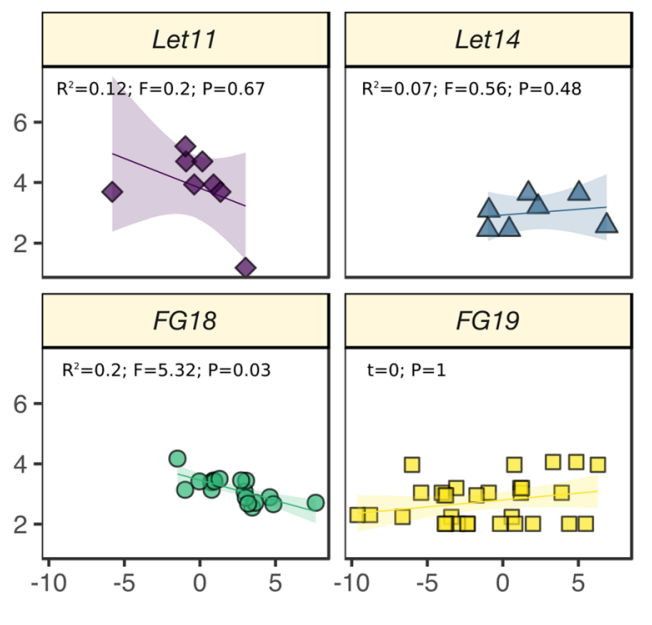


Fig. 3 Relationship between nearest-neighbor distance (NND) and calling-perch height in A. femoralis. a Fitted regression line from a linear regression mixed model with "data set" as a co-variable (diamonds: Let11 $(\mathrm{N}$ $=8)$; triangles: Let14 $(N=7)$; circles: $F G 18(N=18)$; squares: $F G 19(N=12))$. b Simple linear regression models for every "data set." Shaded regions indicate $95 \%$ confidence intervals a

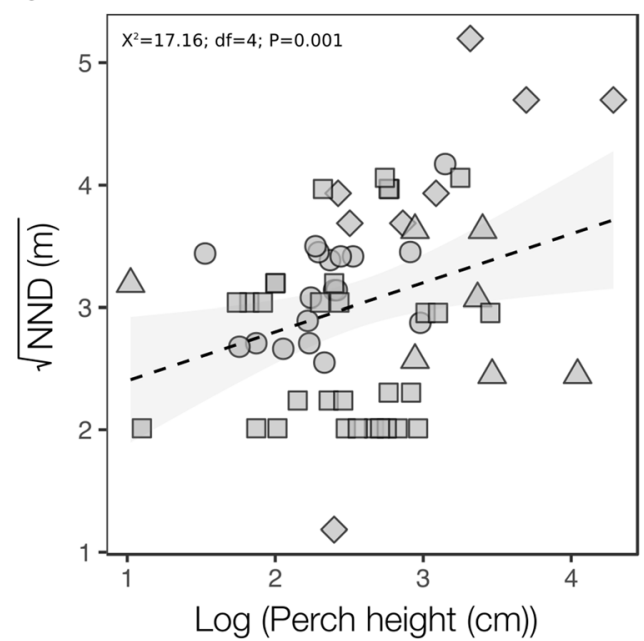

b

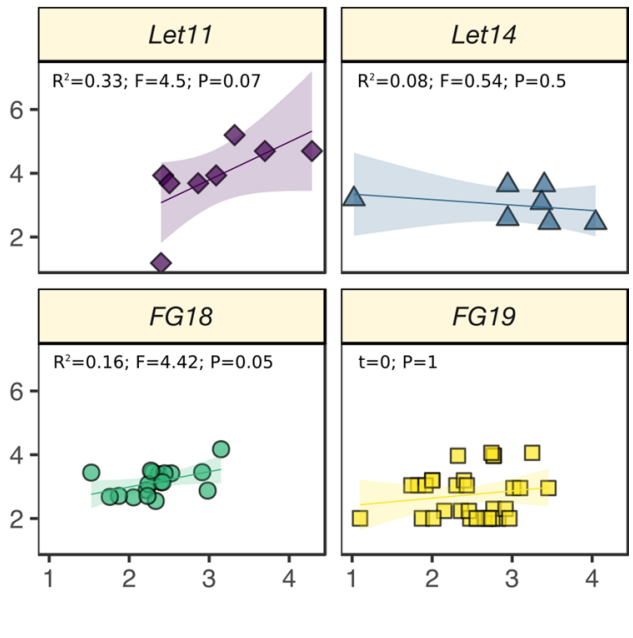

SPLs of the advertisement call of $A$. femoralis males were statistically not repeatable ( $R=0.18, P=0.14$; Fig. 4). Conversely, calling-perch height was statistically repeatable across the three trials $(R=0.36, P=0.02$; Fig. 4$)$.

In our propagation experiments, signals broadcast at $76 \mathrm{~dB}$ from 0 -cm height propagated equally as signals at $73 \mathrm{~dB}$ from 20 -cm height (planned lsmeans contrast: $t=-2.51, P=0.22$; Fig. 5; Supplementary Material Table S1) while signals broadcast at $81 \mathrm{~dB}$ from $0-\mathrm{cm}$ height propagate farther than signals at $76 \mathrm{~dB}$ from 20-cm height (planned lsmeans contrast: $t=$ 10.48, $P<0.001$; Fig. 5; Supplementary Material Table S1). We found no significant differences between 0 and $10 \mathrm{~cm}$ or between 10 and $20 \mathrm{~cm}$ (Fig. 5; Supplementary Material Table S1) of perch height with test signals broadcast at most of the three different intensities (73, 76, and $81 \mathrm{~dB}$; Fig. 5). However, perch height differences between 0 and $20 \mathrm{~cm}$ significantly increase the sound propagation (planned lsmeans contrast: all $P<0.001$; Fig. 5; Supplementary Material Table S1).

\section{Discussion}

Numerous studies have shown the positive effect of callingperch height on sound propagation on long- and shortdistance communication systems. Sound is attenuated when closer to the ground because of the dense vegetation and ground effect (Marten and Marler 1977; Richard and Wiley 1980; Wells and Schwartz 1982; Forrest 1994; Schwartz et al. 2015). In the case of A. femoralis, our results suggest an adjustment to the hypothesis of a general positive effect of calling-perch height on signal effectiveness, where males take advantage of the signal-enhancing effects of calling from high perches without affecting the effectiveness of acoustic spacing with conspecifics.
As acoustic communication mediates reproductive and territorial behaviors (e.g., territorial advertising, aggressive encounters, mating), evolution exerts selective pressures on the signals and/or on behavioral adaptations (Gerhardt 1994; Owings and Morton 1998). Two selective pressures might be driving the behavioral plasticity regarding calling amplitude and the choice of calling-perch heights in A. femoralis. First, because calling with higher amplitude is energetically costly (Prestwich 1994; Ryan 1988), calling at higher perches and thereby reducing attenuation (Morton 1975; Marten and Marler 1977) allows the frogs to save energy by producing calls with lower amplitude but still sufficient propagation. Second, calling at elevated sites above the ground level enhance acoustic and visual conspicuousness to females and conspecific males, as has been shown in the glass frog Centrolenella fleischmanni (Greer and Wells 1980) and in the strawberry poison frog Oophaga pumilio (Kats et al. 2012). However, possible costs include an increased visual and acoustic conspicuousness also towards predators (Haff and Magrath 2011; Dugas et al. 2015), which could be counteracted by either reducing the amplitude of the signal (Tuttle and Ryan 1982) or developing visual antipredatory mechanisms (e.g., cryptic appearance, Batesian or Müllerian mimicry; Ruxton et al. 2004; Amézquita et al. 2017).

We present evidence of both antipredator mechanisms in A. femoralis. First, males had a significant intra-individual variation in advertisement call amplitude, but they maintained relatively small variation in the calling-perch height (Fig. 4), indicating that they can actively vary the calling amplitude. Plasticity in the call amplitude has been shown in some anuran species in response to ambient noise (Lopez et al. 1988; Penna et al. 2005; Cunnington and Fahrig 2010; Halfwerk et al. 2016), and also by exploiting signal-enhancing structures (Lardner and bin Lakim 2002). To our knowledge, this is the first study that shows evidence of call amplitude 


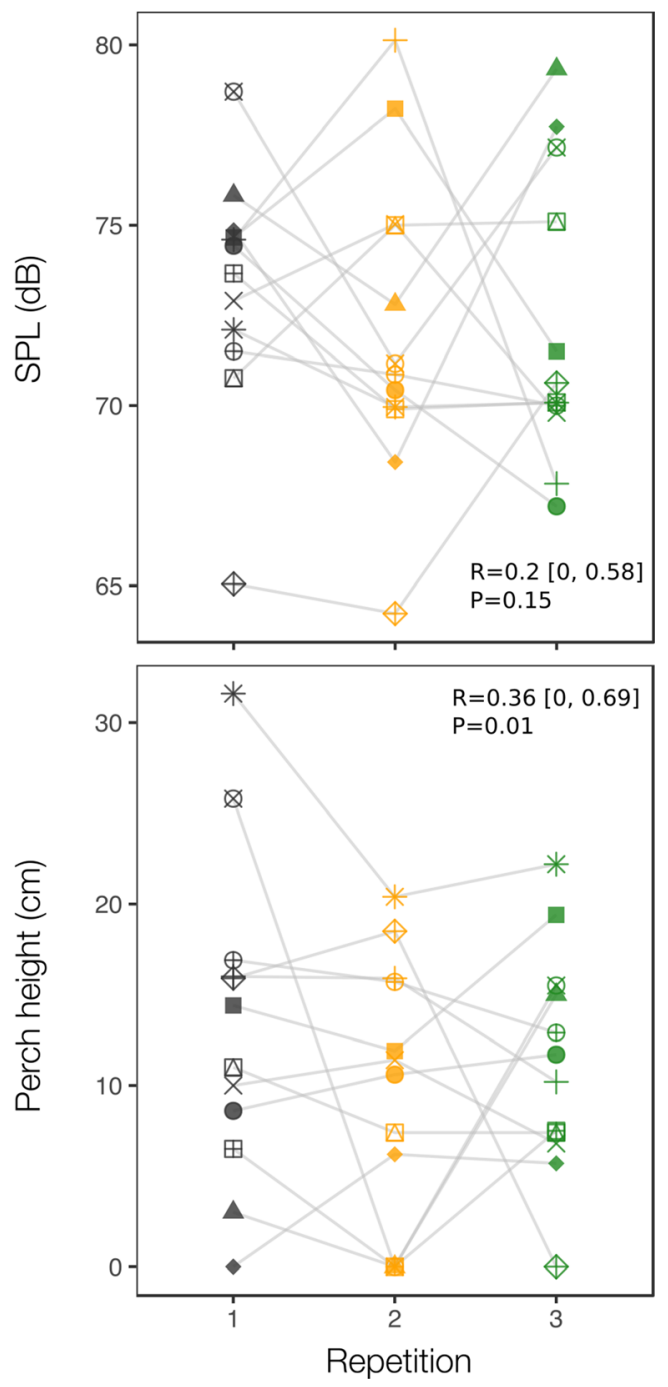

Fig. 4 Plot showing individual measurements in A. femoralis of soundpressure levels (SPLs) of the advertisement call (upper plot) and callingperch height (lower plot) over three trials. Symbols represent each individual. We estimated repeatability $(R)$ and $95 \%$ confidence intervals (in square brackets)

adjustment in a territorial frog. Second, in our two study populations, A. femoralis co-occurs with their toxic "co-mimic" Ameerega hahneli. The two species have similar brightly colored femoral patches and dorsolateral lines, with reflectance spectra that do not differ significantly at the Tanimboca natural reserve near Leticia (see Online Resource ESM1).

Several studies have shown that acoustic communicating species use the amplitude of the signal as a reliable cue to assess neighbor distances, allowing acoustic spacing between neighbors (Naguib 1997; Nelson 2000). However, if neighboring males are able to modulate their call amplitude, it is unreliable to use only SPL of the signal to infer neighbor proximity (Richards 1981; Morton 1982). In our study, SPL did not predict the inter-individual distances between calling A. femoralis males. Considering that $A$. femoralis can vary the
SPL Broadcasted (dB)

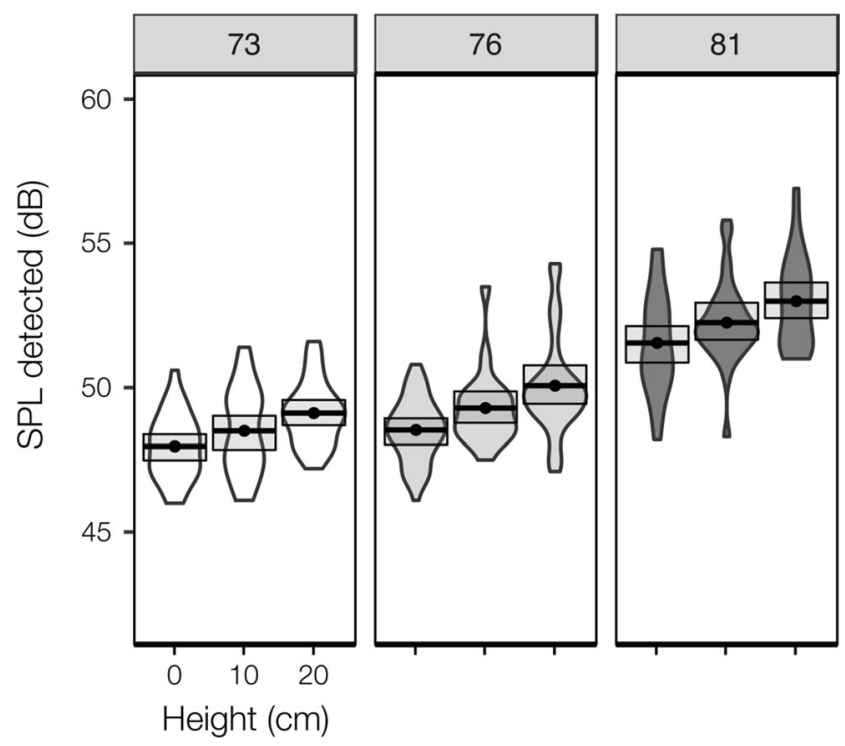

Fig. 5 Violin plots showing the effect of the calling-perch height on the detected SPL at three different broadcasted SPLs and at $6 \mathrm{~m}$ of horizontal distance from the loudspeaker. Black dots and horizontal bars denote means and shaded square boxes denote $99.9 \%$ confidence intervals after Bonferroni's correction

calling amplitude, acoustic ranging and territory spacing may therefore depend on other factors than SPL alone. Indeed, another study in the "Pararé field camp" population suggested that males use also other cues independent from SPL, like spectral degradation or reverberation, for assessing neighbor distance (Ringler et al. 2017). However, SPL had a negative effect on the NND in the FG18 data set (Fig. 2b). One possible explanation for this unexpected result is that signals close to the ground are more prone to degradation and likely they sound as if they would originate from further away than signals produced from higher perches, even when they are at a lower SPL. Therefore, frogs assessing their neighbor's distance (also) from signal degradation (Ringler et al. 2017) consequently may settle closer to more degraded signals, assuming they come from further away. This third effect might add to the concomitant effect of signal-source height and the amplitude of the signal on inter-individual spacing in A. femoralis.

In line with the hypothesis that male frogs benefit from calling at elevated perches to increase inter-individual spacing, by improving the sound propagation (Greer and Wells 1980; Wells and Schwartz 1982; Gerhardt et al. 1989), we found that higher perched A. femoralis males had larger NND. Several studies have shown that the source height of the signal affects the propagation distance, with a pronounced effect on sound attenuation below $1 \mathrm{~m}$ above the ground (Morton 1975; Marten and Marler 1977; Wiley and Richards 1982; Forrest 1994; Kime et al. 2000; Parris 2002). 
In fact, under realistic field conditions, our propagation experiments showed that calling-perch heights of just $20 \mathrm{~cm}$ significantly increase the signal propagation compared to calling perches on the ground. Therefore, males calling close to the ground could suffer disadvantages from unwanted signal reflection and/or excess attenuation due to ground cover. Interestingly, our experimental data also show that softer signals produced at higher calling perches propagate as well as louder signals from the ground. That is, frogs might spend less metabolic energy in calling (i.e., low rate of oxygen consumption to produce low-amplitude calls) by exploiting the enhancing effects on sound propagation of calling from elevated positions (Ryan 1988; Forrest 1994). Then, our results suggest that reducing the calling amplitude when perching higher might have concomitant benefits associated with energy saving, antipredator strategies, and acoustic communication optimization. Further propagation experiments are needed with the speaker and the SPL meter positioned on the average of typical calling-perch height in order to mimic the natural position of both senders and receivers.

It is noteworthy that the relationships between calling amplitude, calling-perch height, and NND did not follow the same pattern across the different data sets. This suggests that the acoustic behavior in A. femoralis is more complex and may depend on additional ecological factors like weather conditions, motivational state, or population density. Also, we cannot discard that the inverse relationship between call amplitude and calling-perch height could be an epiphenomenon of multimodal signaling, where males perch higher to improve the sound propagation but also increase the visibility of the vocal sac towards neighboring males and females (Narins et al. 2003; Halfwerk et al. 2016). Further research is needed to clarify the reasons of such variation in the vocal behavior across different locations and time periods. Likewise, we present evidence for elevationrelated changes in call amplitude in A. femoralis males for just one location and year (FG19). However, to claim a behavioral adaptation across the $A$. femoralis species complex (Amézquita et al. 2009; Grant et al. 2017), further experimental studies are needed to assess the flexibility of territorial frogs' calling amplitude in different populations, for instance, by measuring SPLs after presenting calling-perch structures with different heights within male's territories.

Behavioral adjustments may grant benefits when selected or developed in a specific context (Sol et al. 2013). In the acoustic communication context, animals must interact with the environment and adjust their calling behavior to improve their communication. Overall, our study suggests that highly territorial frog males can adjust their calling behavior by exploiting the signalenhancing effects of elevated calling positions and producing calls with lower amplitude. We propose that such behavioral adjustment can be advantageous to enhance the effectiveness of communication through improving call propagation, energy saving, and minimizing predation risk.
Acknowledgments We are grateful to S. Chaloupka for the help in the propagation experiments. We thank A. Lembens, V. Canoine, and G. Raboisson for providing field assistance and two anonymous reviewers for the helpful comments on this article. We thank the Nouragues research field station (managed by CNRS) which benefits from "Investissement d'Avenir" grants managed by Agence Nationale de la Recherche (AnaEE France ANR11-INBS-0001; Labex CEBA ANR-10-LABX-25-01) and Tanimboca Natural Reserve for the logistic support. Additional support for the study at Leticia was provided by grants to CR from the Research Committee of the Faculty of Sciences at the Universidad de Los Andes, Bogotá.

Authors' contribution $\mathrm{CR}, \mathrm{WH}$, and AA conceived and performed the experiments. $\mathrm{CR}, \mathrm{WH}, \mathrm{AP}$, and $\mathrm{MR}$ wrote the manuscript. $\mathrm{CR}$ analyzed the data.

Funding information Open access funding provided by Austrian Science Fund (FWF). This work was supported by the Austrian Science Fund (FWF), W1262-B29, and by an Erwin Schrödinger Fellowship (FWF J3868) to MR.

Data availability The datasets generated and/or analyzed during the current study are available in the Open Science Framework (OSF; https://osf. io/q7rz9/?view_only=ae0734f4a6c54808acd2785ff0dc0119).

\section{Compliance with ethical standards}

Conflict of interest The authors declare that they have no conflict of interest.

Ethics approval All experiments were conducted in strict accordance with current French, European Union, and Colombian laws and were approved by the Animal Ethics and Experimentation Board of the University of Vienna (No. 2018-009). Our study was approved by the scientific committees of the "Nouragues Ecological Research Station" and "Tanimboca Natural Reserve" where field work was conducted. We adhere to the "Guidelines for the use of live amphibians and reptiles in field and laboratory research" by the Herpetological Animal Care and Use Committee (HACC) of the American Society of Ichthyologists and Herpetologists.

Consent to participate The author declares that all co-authors of the contribution are aware of the fact and have agreed to being so named.

Consent for publication The author guarantees that the Contribution to the Work has not been previously published elsewhere. All co-authors are aware of the fact and agreed to being so named.

Code availability The $\mathrm{R}$ code generated to analyze the data during the current study is available in the Open Science Framework (OSF; https:// osf.io/q7rz9/?view_only=ae0734f4a6c54808acd2785ff0dc0119).

Open Access This article is licensed under a Creative Commons Attribution 4.0 International License, which permits use, sharing, adaptation, distribution and reproduction in any medium or format, as long as you give appropriate credit to the original author(s) and the source, provide a link to the Creative Commons licence, and indicate if changes were made. The images or other third party material in this article are included in the article's Creative Commons licence, unless indicated otherwise in a credit line to the material. If material is not included in the article's Creative Commons licence and your intended use is not permitted by statutory regulation or exceeds the permitted use, you will need to obtain permission directly from the copyright holder. To view a copy of this licence, visit http://creativecommons.org/licenses/by/4.0/. 


\section{References}

Amézquita A, Castellanos L, Hödl W (2005) Auditory matching of male Epipedobates femoralis (Anura: Dendrobatidae) under field conditions. Anim Behav 70:1377-1386

Amézquita A, Hödl W, Lima AP, Castellanos L, Erdtmann L, de Araújo MC (2006) Masking interference and the evolution of the acoustic communication system in the Amazonian dendrobatid frog Allobates femoralis. Evolution 60:1874-1887

Amézquita A, Lima AP, Jehle R, Castellanos L, Ramos Ó, Crawford AJ, Gasser H, Hödl W (2009) Calls, colours, shape, and genes: a multitrait approach to the study of geographic variation in the Amazonian frog Allobates femoralis. Biol J Linn Soc 98:826-838

Amézquita A, Ramos Ó, González MC, Rodríguez C, Medina I, Simões PI, Lima AP (2017) Conspicuousness, color resemblance, and toxicity in geographically diverging mimicry: the pan-Amazonian frog Allobates femoralis. Evolution 71:1039-1050

AmphibiaWeb (2020) AmphibiaWeb: Information on amphibian biology and conservation. University of California. Berkeley, CA, USA, www.amphibiaweb.org

Bongers F, Charles-Dominique P, Forget PM, Théry M (2013) Nouragues: dynamics and plant-animal interactions in a neotropical rainforest. Springer Science \& Business Media, New York

Boulenger GA (1883) On a collection of frogs from Yurimaguas, Huallaga River, northern Peru. Proc Zool Soc Lond 51:635-638

Brenowitz EA (1989) Neighbor call amplitude influences aggressive behavior and intermale spacing in choruses of the Pacific Treefrog (Hyla regilla). Ethology 83:69-79

Brenowitz EA, Wilczynski W, Zakon HH (1984) Acoustic communication in spring peepers. Environmental and behavioral aspects. J Comp Physiol A 155:585-592

Bro-Jørgensen J (2010) Dynamics of multiple signaling systems: animal communication in a world in flux. Trends Ecol Evol 25:292-300

Brumm H, Todt D (2002) Noise-dependent song amplitude regulation in a territorial songbird. Anim Behav 63:891-897

Brumm H, Todt D (2004) Male-male vocal interactions and the adjustment of song amplitude in a territorial bird. Anim Behav 67:281-286

Corporación para el Desarrollo sostenible del sur de la Amazonía CORPOAMAZONIA (2006) Plan de ordenación y manejo de la microcuenca de la quebrada Yahuarcaca. CORPOAMAZONIA, Leticia, Colombia

Cunnington GM, Fahrig L (2010) Plasticity in the vocalizations of anurans in response to traffic noise. Acta Oecol 36:463-470

de Luna AG, Hödl W, Amézquita A (2010) Colour, size and movement as visual subcomponents in multimodal communication by the frog Allobates femoralis. Anim Behav 79:739-745

Duellman WE, Pyles RA (1983) Acoustic resource partitioning in anuran communities. Copeia 1983:639-649

Dugas MB, Halbrook SR, Killius AM, del Sol JF, Richards-Zawacki CL (2015) Colour and escape behaviour in polymorphic populations of an aposematic poison frog. Ethology 121:813-822

Forrest TG (1994) From sender to receiver: propagation and environmental effects on acoustic signals. Am Zool 34:644-654

Gasser H, Amézquita A, Hödl W (2009) Who is calling? Intraspecific call variation in the aromobatid frog Allobates femoralis. Ethology 115: 596-607

Gerhardt HC (1994) The evolution of vocalization in frogs and toads. Annu Rev Ecol Syst 25:293-324

Gerhardt HC, Huber F (2002) Acoustic communication in insects and anurans: common problems and diverse solutions. University of Chicago Press, Chicago

Gerhardt HC, Diekamp B, Ptacek M (1989) Inter-male spacing in choruses of the spring peeper, Pseudacris (Hyla) crucifer. Anim Behav $38: 1012-1024$
Göd M, Franz A, Hödl W (2007) The influence of internote-interval variation of the advertisement call on the phonotactic behaviour in male Allobates femoralis (Dendrobatidae). Amphibia-Reptilia 28:227-234

Grant T, Rada M, Anganoy-Criollo M, Batista A, Dias PH, Jeckel AM, Machado DJ, Rueda-Almonacid JV (2017) Phylogenetic systematics of dart-poison frogs and their relatives revisited (Anura: Dendrobatoidea). S Am J Herpetol 12:S1-S90

Greer BJ, Wells KD (1980) Territorial and reproductive behavior of the tropical american frog Centrolenella fleischmanni. Herpetologica $36: 318-326$

Haff TM, Magrath RD (2011) Calling at a cost: elevated nestling calling attracts predators to active nests. Biol Lett 7:493-495

Halfwerk W, Lea AM, Guerra MA, Page R, Ryan M (2016) Vocal responses to noise reveal the presence of the Lombard effect in a frog. Behav Ecol 27:669-676

Hijmans RJ, Williams E, Vennes C, Hijmans, MR (2017) Package "geosphere", https://cran.r-project.org/web/packages/geosphere/

Hödl W (1983) Phyllobates femoralis (Dendrobatidae): rufverhalten und akustische Orientierung der Männchen (Freilandaufnahmen). Wissenschaftligher Film 30:12-19

Hödl W (1977) Call differences and calling site segregation in anuran species from Central Amazonian floating meadows. Oecologia 28:351-363

Hödl W, Amézquita A, Narins PM (2004) The rôle of call frequency and the auditory papillae in phonotactic behavior in male Dart-poison frogs Epipedobates femoralis (Dendrobatidae). J Comp Physiol A 190:823-829

Jameson DL (1954) Social patterns in the leptodactylid frogs Syrrhophus and Eleutherodactylus. Copeia 1954:36-38

Johansson T (2011) Hail the impossible: p-values, evidence and likelihood. Scand 52:113-125

Kaefer IL, Montanarin A, Da Costa RS, Lima AP (2012) Temporal patterns of reproductive activity and site attachment of the brilliantthighed frog Allobates femoralis from central Amazonia. J Herpetol 46:549-554

Kats LB, Bucciarelli GM, Schlais DE, Blaustein AR, Han BA (2012) Ultraviolet radiation influences perch selection by a neotropical poison-dart frog. PLoS ONE 7:e51364

Kime NM, Turner WR, Ryan MJ (2000) The transmission of advertisement calls in Central American frogs. Behav Ecol 11:71-83

Lardner B, Bin Lakim M (2002) Tree-hole frog exploit resonance effects. Nature 420:475-475

Lenth R (2016) Least-squares means: the R package 1smeans. J Stat Softw 69:1-33

Lombard E (1911) Le signe de l'elévation de la voix. Ann Mal Oreille Larynx 37:101-119

Lopez PT, Narins P, Lewis ER, Moore SW (1988) Acoustically induced call modification in the white-lipped frog, Leptodactylus albilabris. Anim Behav 36:1295-1308

Lötters S, Jungfer KH, Henkel F, Schmidt W (2007) Poison frogs: biology, species and captive husbandry. Edition Chimaira, Frankfurt am Main, Germany

Love EK, Bee MA (2010) An experimental test of noise-dependent voice amplitude regulation in Cope's grey treefrog, Hyla chrysoscelis. Anim Behav 80:509-515

Marten K, Marler P (1977) Sound transmission and its significance for animal vocalization. Behav Ecol Sociobiol 2:271-290

Montanarin A, Kaefer IL, Lima AP (2011) Courtship and mating behaviour of the brilliant-thighed frog Allobates femoralis from Central Amazonia: implications for the study of a species complex. Ethol Ecol Evol 23:141-150

Morton ES (1975) Ecological sources of selection on avian sounds. Am Nat 109:17-34

Morton ES (1982) Grading, discreteness, redundancy, and motivationstructural rules. In: Kroodsma DE, Miller EH, Ouellet H (eds) Acoustic communication in birds: production, perception, and design features of sound. Academic Press, New York, pp 183-212 
Naguib M (1997) Use of song amplitude for ranging in Carolina wrens, Thryothorus ludovicianus. Ethology 103:723-731

Nakagawa S, Schielzeth H (2010) Repeatability for Gaussian and nonGaussian data: a practical guide for biologists. Biol Rev 85:935-956

Narins PM, Hödl W, Grabul DS (2003) Bimodal signal requisite for agonistic behavior in a dart-poison frog, Epipedobates femoralis. $\mathrm{P}$ Natl Acad Sci USA 100:577-580

Narins PM, Feng AS, Fay RR (2006) Hearing and sound communication in amphibians. Springer, New York

Nelson BS (2000) Avian dependence on sound pressure level as an auditory distance cue. Anim Behav 59:57-67

Owings DH, Morton ES (1998) Animal vocal communication: a new approach. Cambridge University Press, Cambridge

Parris KM (2002) More bang for your buck: the effect of caller position, habitat and chorus noise on the efficiency of calling in the spring peeper. Ecol Model 156:213-224

Prestwich KN (1994) The energetics of acoustic signaling in anurans and insects. Am Zool 34:625-643

Pröhl H (2005) Territorial behavior in dendrobatid frogs. J Herpetol 39: 354-365

R Core Team (2017) R: a language and environment for statistical computing. R Foundation for Statistical Computing, Vienna, Austria, https://www.r-project.org/

Richards DG (1981) Estimation of distance of singing conspecifics by the Carolina wren. Auk 98:127-133

Ringler M, Ringler E, Mendoza DM, Hödl W (2011) Intrusion experiments to measure territory size: development of the method, tests through simulations, and application in the frog Allobates femoralis. PLoS ONE 6:e25844

Ringler E, Pašukonis A, Hödl W, Ringler M (2013) Tadpole transport logistics in a Neotropical poison frog: indications for strategic planning and adaptive plasticity in anuran parental care. Front Zool 10: 67

Ringler M, Mangione R, Pašukonis A, Rainer G, Gyimesi K, Felling J, Kronaus H, Réjou-Méchain M, Chave J, Reiter K, Ringler E (2014) High-resolution forest mapping for behavioural studies in the Nature Reserve "Les Nouragues", French Guiana. J Maps 12:26-32

Ringler M, Hödl W, Ringler E (2015) Populations, pools, and peccaries: simulating the impact of ecosystem engineers on rainforest frogs. Behav Ecol 26:340-349

Ringler M, Szipl G, Hödl W, Khil L, Kofler B, Lonauer M, Provin C, Ringler E (2017) Acoustic ranging in poison frogs - it is not about signal amplitude alone. Behav Ecol Sociobiol 71:114

Robertson JG (1984) Acoustic spacing by breeding males of Uperoleia rugosa (Anura: Leptodactylidae). Z Tierpsychol 64:283-297

Rodríguez C, Hödl W (2020) Sound radiation pattern of the advertisement call of the highly territorial poison frog Allobates femoralis. Behav Process 170:103996

Roithmair ME (1992) Territoriality and male mating success in the dartpoison frog, Epipedobates femoralis (Dendrobatidae, Anura). Ethology 92:331-343
Ruxton GD, Sherratt TN, Speed MP (2004) Avoiding attack: the evolutionary ecology of crypsis, warning signals and mimicry. Oxford University Press, Oxford

Ryan MJ (1988) Energy, calling, and selection. Am Zool 28:885-898

Schwartz JJ, Hunce R, Brandon L, Powers K (2015) Calling site choice and its impact on call degradation and call attractiveness in the gray tree frog, Hyla versicolor. Behav Ecol Sociobiol 70:1-19

Shen JX, Xu ZM (2016) The Lombard effect in male ultrasonic frogs: regulating antiphonal signal frequency and amplitude in noise. Sci Rep 6:27103

Sol D, Lapiedra O, Gonzáles-Lagos C (2013) Behavioural adjustments for a life in the city. Anim Behav 85:1101-1112

Sorjonen J (1986) Factors affecting the structure of song and the singing behaviour of some Northern European passerine birds. Behaviour 98:286-304

Stückler S, Ringler M, Pašukonis A, Weinlein S, Hödl W, Ringler E (2019) Spatio-temporal characteristics of the prolonged courtship in brilliant-thighed poison frogs, Allobates femoralis. Herpetologica 75:268-279

Toledo LF, Martins IA, Bruschi DP, Passos MA, Alexandre C, Haddad CF (2014) The anuran calling repertoire in the light of social context. Acta Ethol 18:87-99

Tumulty JP, Pašukonis A, Ringler M, Forester JD, Hödl W, Bee MA (2018) Brilliant-thighed poison frogs do not use acoustic identity information to treat territorial neighbours as dear enemies. Anim Behav 141:203-220

Walker TJ, Forrest TG (1989) Mole cricket phonotaxis: effects of intensity of synthetic calling song (Orthoptera, Gryllotalpidae, Scapteriscus acletus). Fla Entomol 72:655-659

Wells KD (2007) The ecology and behavior of amphibians. University of Chicago Press, Chicago

Wells KD, Schwartz JJ (1982) The effect of vegetation on the propagation of calls in the Neotropical frog Centrolenella fleischmanni. Herpetologica 38:449-455

Wells KD, Schwartz JJ (2007) The behavioral ecology of anuran communication. In: Narins P, Feng AS, Fay RR (eds) Hearing and sound communication in amphibians. Springer, Berlin, pp 44-86

Wilczynski W, Brenowitz EA (1988) Acoustic cues mediate inter-male spacing in a neotropical frog. Anim Behav 36:1054-1063

Wiley RH, Richards DG (1982) Adaptations for acoustic communication in birds. In: Kroodsma DE, Miller EH (eds) Sound transmission and signal detection. Academic Press, New York, pp 131-181

Zeileis A, Hothorn T (2002) Diagnostic checking in regression relationships. R News 2:7-10

Zhao L, Sun X, Chen Q, Yang Y, Wang J, Ran J, Brauth S, Tang Y, Cui J (2018) Males increase call frequency, not intensity, in response to noise, revealing no Lombard effect in the little torrent frog. Ecol Evol 8:11733-11741

Publisher's note Springer Nature remains neutral with regard to jurisdictional claims in published maps and institutional affiliations. 